\title{
Septic arthritis of the temporomandibular joint leading to an epidural abscess
}

\author{
Joern Wittig, Farzad Borumandi, Alexander Gaggl, Johannes Hachleitner
}

Oral and Maxillofacial Surgery, University Hospital Salzburg, Salzburg, Austria

\section{Correspondence to}

Dr Joern Wittig,

joern.wittig@gmx.de

Accepted 26 May 2018

\section{SUMMARY}

Septic arthritis of the temporomandibular joint (TMJ) is rare, but patients with this diagnosis are at high risk for significant morbidity. We present a case of a 15-yearold man who presented with increasing trismus for 3 days. He had only minimal discomfort and swelling of the right cheek and temporal region, and pericoronitis of an impacted wisdom tooth was suspected. Under intravenous antibiotics, pain subsided, but trismus and a slight swelling remained. CT scan showed septic arthritis of the TMJ with an abscess formation penetrating into the epidural space. Immediate drainage and craniotomy were performed. Under intravenous antibiotics, the patient made a full recovery. The source of infection remained undetermined. To our knowledge, this is the first reported case of septic arthritis of the TMJ spreading into the epidural space.

\section{BACKGROUND}

Septic arthritis of the temporomandibular joint (TMJ) is rare and is reported with an incidence of 2-10 cases per $100000 .{ }^{1}$ The symptoms are pain, swelling, fever and loss of function. ${ }^{2}$ The most common bacteria causing this infection are Staphylococcus aureus, Neisseria gonorrhoea, Haemophilus influenzae and Streptococcus. The microorganisms can spread either locally or by haematogenous dissemination. $^{23}$ Iatrogenic origin is reported after joint injection or arthroscopy. ${ }^{3} 4$ Direct spread from a contiguous site can have different origins. Septic arthritis is described as complication of otitis externa ${ }^{5}$ or as sequelae after oral surgery operations like removal of third molars. ${ }^{6}$ General factors like systemic and autoimmune disease (ie, rheumatoid arthritis, diabetes, immunosuppression, hypogammaglobulinaemia) or prolonged use of systemic

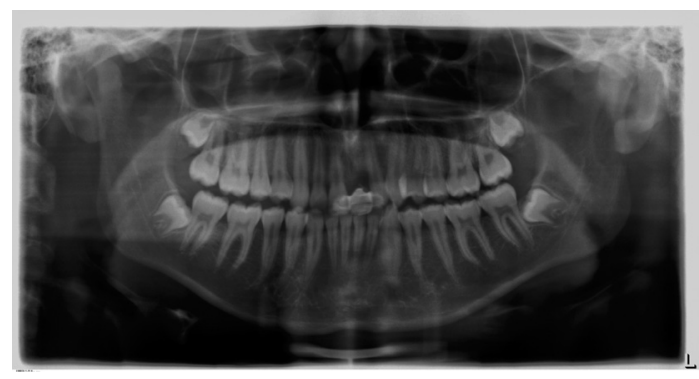

Figure 1 Orthopantomography showing the impacted wisdom teeth, no dental abnormalities. The joint space of the right TMJ is enlarged. TMJ, temporomandibular joint. steroids can be predisposing factors for septic arthritis. $^{7}$

Epidural abscesses of the central nervous system are rare and can be located in the intracranial or spinal compartment. Three major pathways can infect the epidural space: haematogenous spread of bacteria, direct inoculation as a result of trauma or surgical intervention or direct extension of an infection from neighbouring structures. ${ }^{8}$ The most common risk factors for intracranial epidural abscesses (ICEAs) are frontal sinus infection, post-traumatic infection, recent surgical intervention and congenital defects of the cranial base. ${ }^{9}$

\section{CASE PRESENTATION}

A 15-year-old man presented to our outpatient department with increasing trismus for 3 days and a slight swelling of the right cheek and infratemporal swelling for 1 day. Apart from that, the patient was healthy. There was no recent treatment or intervention in the medical history. The patient was comfortable with very little pain. The temperature was $38.2^{\circ} \mathrm{C}$, laboratory findings included white blood cell count of $10720 /$ $\mu \mathrm{L}$ and $\mathrm{C}$ reactive protein of $12.9 \mathrm{mg} / \mathrm{dL}$. Orthopantomography (figure 1) showed no dental focus beside four impacted wisdom teeth. The considerably larger joint space in the right TMJ was initially not noticed. The patient was admitted to our hospital with the diagnosis of pericoronitis of the lower right wisdom tooth. Intravenous antibiotics with Cefazolin were administered, scaling was performed and oral hygiene was intensified. The swelling decreased, but as mouth opening did not improve, the patient underwent contrast CT on the third day. At that time, the patient had no pain. The CT revealed an abscess formation in the TMJ extending beneath the temporal muscle and penetrating into the epidural temporal region (figure 2). The patient was transferred to the department of neurosurgery. MRI showed the abscess but no intracerebral lesion (figures 3 and 4). Drainage of the infratemporal abscess was performed by a question mark incision and subsequent craniotomy for the drainage of the epidural abscess. The TMJ space was communicating with the infratemporal abscess formation and was drained and irrigated through the same approach. The antibiotic therapy was extended by Vancomycin to cover potential infection by methicillin-resistant Staphylococcus aureus or Enterococci. Postoperative care on the intermediate care unit for 2 days was uneventful. Trismus subsided rapidly. Microbiology identified 


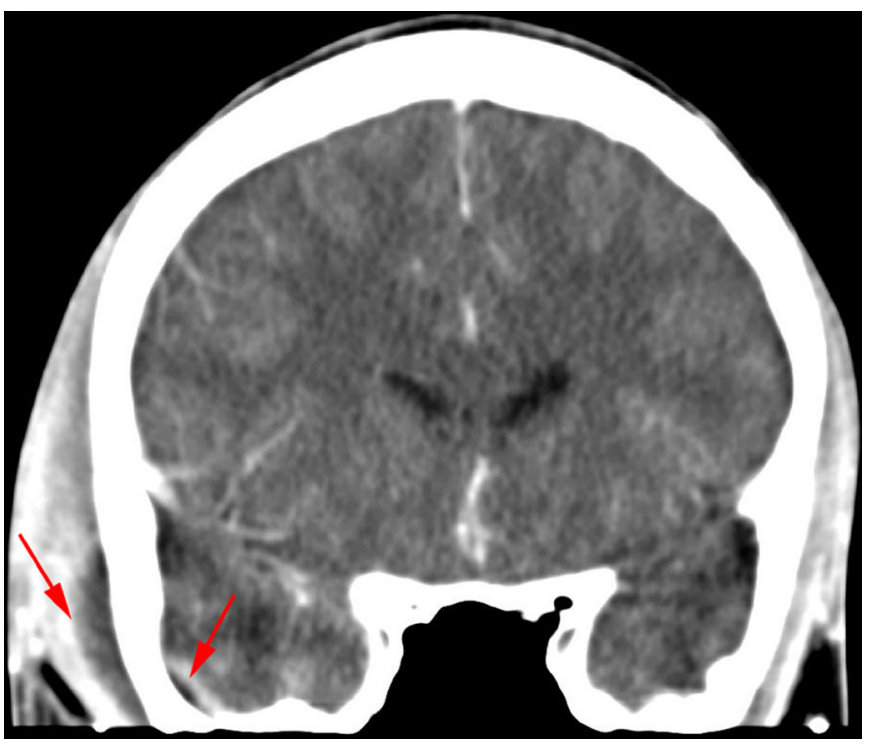

Figure 2 CT scan showing fluid collection beneath the temporalis muscle and in the epidural space.

Staphylococcus aureus as causative microorganism, which was sensitive to Cefazolin. Antibiotic treatment was de-escalated to Cefazolin.

\section{INVESTIGATIONS}

To find out the cause of the infection, several investigations were performed. ENT examination showed no abnormality. Echocardiography showed no endocarditis or valve alteration. A fludeoxyglucose positron emission tomography was performed after 9 days without pathological findings.

\section{DIFFERENTIAL DIAGNOSIS}

Discomfort in the region of the TMJ has various differential diagnoses, it can be caused by disc displacement, osteoarthrosis, rheumatoid arthritis, psoriatic arthritis, septic arthritis, neoplasia, metastasis, synovial chondromatosis, osteomyelitis, pleomorphic adenoma, parotitis and other rare conditions.

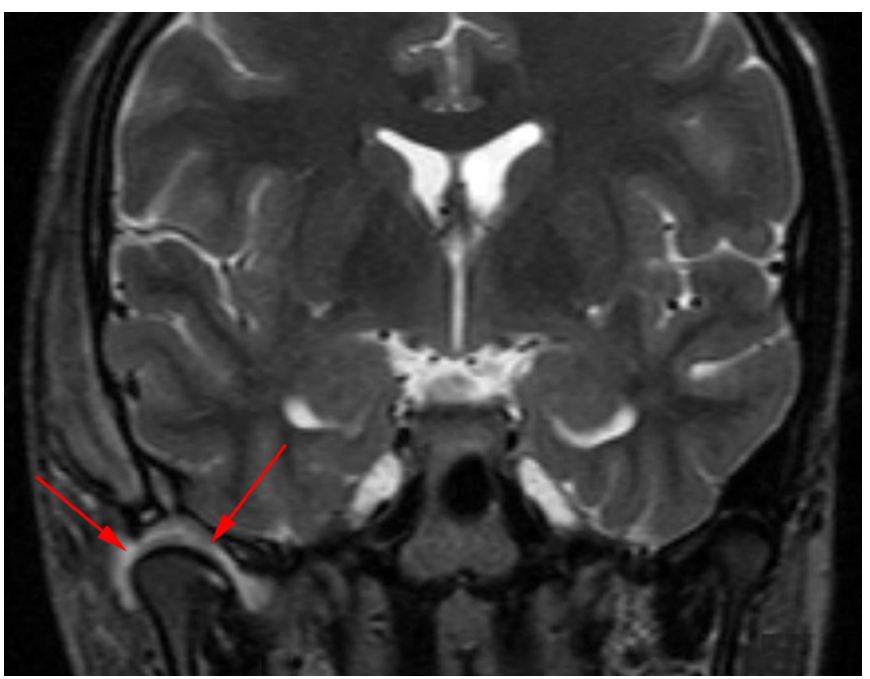

Figure 3 MRI showing fluid collection in the right TMJ. TMJ, temporomandibular joint.

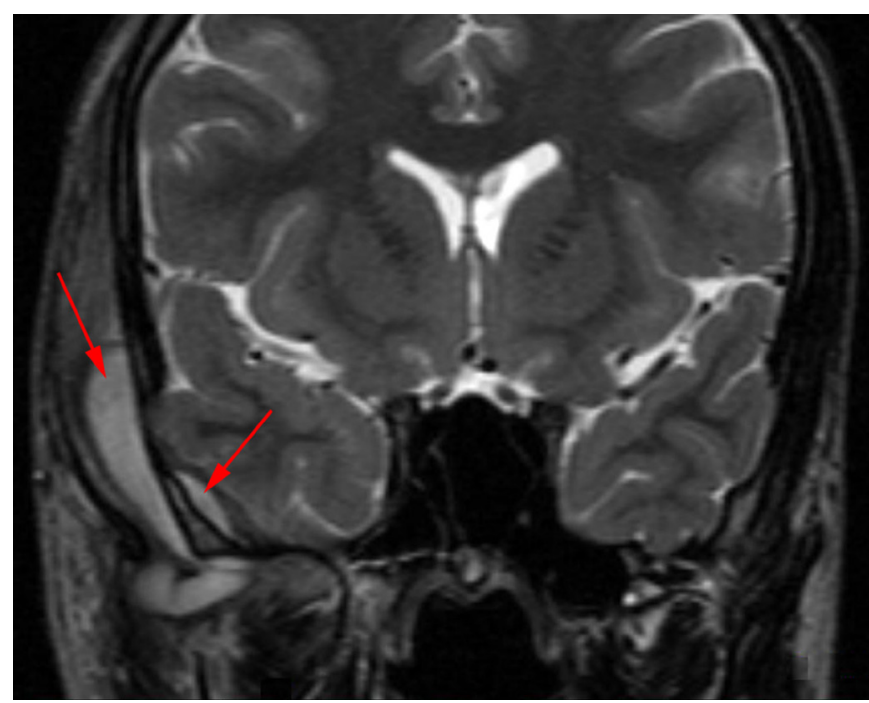

Figure 4 MRI showing the infratemporal and epidural abscess formation.

\section{OUTCOME AND FOLLOW-UP}

A follow-up MRI after 6 weeks showed normal scar tissue. Clinical examination and laboratory findings were unremarkable at this time without signs of infection. Mouth opening was within normal range, and there was no indication for TMJ ankylosis, which is a common sequelae to watch out for inpatients with TMJ septic arthritis.

\section{DISCUSSION}

There are not many reports on septic arthritis of the TMJ. Most of the studies are case reports. In many cases, the arthritis resulted from extension of various head and neck infections. ${ }^{10}$ However, Cai et al reported on 40 cases and showed that most microorganisms are spread haematogenously. ${ }^{3}$ This is confirmed by other studies. ${ }^{1011}$ The focus of haematogenous seeding often remains unknown. ${ }^{12}$ In this case, it is uncertain if the infection was spread haematogenously or by direct extension, the pericoronitis being the only risk factor. As in this case, the most commonly isolated organism from patients with septic arthritis is Staphylococcus aureus. In the literature, Streptococcus species, Neisseria gonorrhoea and Haemophilus influenzae have also been reported. ${ }^{3} 10$

Adjacent to the TMJ in lateral and anterior direction, the infratemporal space is separated only by the joint capsule. This anatomical proximity makes it understandable, that septic arthritis of the TMJ can extend into the infratemporal space by contiguous spread. Infratemporal abscess is also described as Luc's abscess. Concurrent with septic arthritis of the TMJ, it has been reported as sequelae of middle ear infection in children. ${ }^{13}$ Another case report on an 18-year-old woman describes masticatory space and infratemporal abscess after third molar extraction leading to osteomyelitis and septic arthritis of the TMJ. ${ }^{14}$ Trismus and temporal swelling should raise suspicion towards TMJ pathology like septic arthritis and concurrent infratemporal abscess formation. ${ }^{14}$

The temporal bone forms the socket of the TMJ as part of the skull base. It separates the TMJ as well as the infratemporal space from the intracranial space. Given the anatomical proximity, TMJ and/or infratemporal infections may lead to osteomyelitis of the temporal bone and result in intracranial extension via contiguous spread. Nevertheless, we could not find any 
previous report of septic arthritis extending into the intracranial space. Most of the ICEAs are caused by local spread from neighbouring sites like paranasal sinuses or mastoid cells into the epidural space. ${ }^{9}$ However, in this case, the anatomical proximity of the TMJ to the infratemporal and intracranial region in addition to the unremarkable ENT status suggests that septic arthritis of the TMJ is the originating pocket of infection. ICEA is a rare neurological disorder that has even more decreased since the introduction of antimicrobial treatments. Common signs and symptoms are fever, headache, nausea and vomiting, confusion, agitation, seizures, hemiparesis and cranial neuropathies. ${ }^{9}$ In this case, the only symptom present was fever. Early intervention is crucial because the risk of permanent neurological damage or generalised sepsis increases if treatment is delayed. Surgical evacuation of any suppurative collection is the preferred method of treatment. If the ICEA is associated with acute bacterial rhinosinusitis, surgical treatment of the sinusitis should be performed.

\section{Learning points}

- Discomfort in the region of the temporomandibular joint (TMJ) is a common symptom. Concurrent trismus should raise the suspicion towards septic arthritis of the TMJ.

- Swelling in the temporal region could suggest an infratemporal abscess (Luc's abscess).

- Intracranial epidural abscesses most commonly arise from ear or sinus infections. Prompt drainage is mandatory.

Contributors JW: study design, data collection, manuscript writing. FB: data collection, manuscript review. AG: manuscript review. JH: study design, manuscript review

Funding The authors have not declared a specific grant for this research from any funding agency in the public, commercial or not-for-profit sectors.

Competing interests None declared.
Patient consent Obtained.

Provenance and peer review Not commissioned; externally peer reviewed.

(C) BMJ Publishing Group Ltd (unless otherwise stated in the text of the article) 2018. All rights reserved. No commercial use is permitted unless otherwise expressly granted.

\section{REFERENCES}

1 Cai $X Y$, Yang $C$, Zhang $Z Y$, et al. A murine model for septic arthritis of the temporomandibular joint. J Oral Maxillofac Surg 2008;66:864-9.

2 Klüppel LE, Bernabé FB, Primo BT, et al. Septic arthritis of the temporomandibular joint. J Craniofac Surg 2012;23:1752-4.

3 Cai XY, Yang C, Zhang ZY, et al. Septic arthritis of the temporomandibular joint: a retrospective review of 40 cases. J Oral Maxillofac Surg 2010;68:731-8.

4 McCain JP, Zabiegalski NA, Levine RL. Joint infection as a complication of temporomandibular joint arthroscopy: a case report. J Oral Maxillofac Surg 1993;51:1389-92.

5 Thomson HG. Septic arthritis of the temporomandibular joint complicating otitis externa. J Laryngol Otol 1989;103:319-21.

6 Moses JJ, Lange CR, Arredondo A. Septic arthritis of the temporomandibular joint after the removal of third molars. J Oral Maxillofac Surg 1998;56:510-2.

7 Sembronio S, Albiero AM, Robiony M, et al. Septic arthritis of the temporomandibular joint successfully treated with arthroscopic lysis and lavage: case report and review of the literature. Oral Surg Oral Med Oral Pathol Oral Radiol Endod 2007;103:e1-e6.

8 Riddell J, Shuman EK. Epidemiology of central nervous system infection. Neuroimaging Clin NAm 2012:22:543-56.

9 Pradilla G, Ardila GP, Hsu W, et al. Epidural abscesses of the CNS. Lancet Neurol 2009:8:292-300.

10 Leighty SM, Spach DH, Myall RW, et al. Septic arthritis of the temporomandibular joint: review of the literature and report of two cases in children. Int J Oral Maxillofac Surg 1993;22:292-7

11 Goldschmidt MJ, Butterfield KJ, Goracy ES, et al. Streptococcal infection of the temporomandibular joint of hematogenous origin: a case report and contemporary therapy. J Oral Maxillofac Surg 2002;60:1347-53.

12 Ishikawa S, Watanabe T, lino M. Acute septic arthritis of the temporomandibular joint derived from otitis media: a report and review of the English and Japanese literature. Oral Maxillofac Surg 2017;21:83-5.

13 Tsai C, Deramo J, Shen X, et al. Luc's abscess and temporomandibular joint septic arthritis: two rare sequelae of acute otitis media. Pediatr Emerg Care 2017.

14 Gayle EA, Young SM, McKenna SJ, et al. Septic arthritis of the temporomandibular joint: case reports and review of the literature. J Emerg Med 2013;45:674-8.

Copyright 2018 BMJ Publishing Group. All rights reserved. For permission to reuse any of this content visit

http://group.bmj.com/group/rights-licensing/permissions.

BMJ Case Report Fellows may re-use this article for personal use and teaching without any further permission.

Become a Fellow of BMJ Case Reports today and you can:

- Submit as many cases as you like

- Enjoy fast sympathetic peer review and rapid publication of accepted articles

- Access all the published articles

- Re-use any of the published material for personal use and teaching without further permission

For information on Institutional Fellowships contact consortiasales@bmjgroup.com

Visit casereports.bmj.com for more articles like this and to become a Fellow 